\title{
Collaboration Leads to Enhanced Curriculum
}

\author{
J. Valerius ${ }^{1}$; V. Mohan ${ }^{1}$; D. Doctor ${ }^{1}$; W. Hersh ${ }^{1}$ \\ ${ }^{1}$ Oregon Health \& Science University, Portland Oregon, United States
}

\section{Keywords}

Informatics, information technology, health information management, education, collaboration, curriculum enhancement, certification, clinical informatics, professional training, education training and education requirements, workforce education, organizational change management, culture, workflows and human interactions, socio-technical aspects of information technology

\section{Summary}

Background: In 2007, we initiated a health information management (HIM) track of our biomedical informatics graduate program, and subsequent ongoing program assessment revealed a confluence of topics and courses within HIM and clinical informatics (CI) tracks. We completed a thorough comparative analysis of competencies derived from AMIA, AHIMA, and CAHIIM. Coupled with the need to streamline course offerings, the process, described in this paper allowed new opportunities for faculty collaboration, resulted in the creation of a model assessment for best practice in courses, and led to new avenues of growth within the program.

Objective: The objective of the case study is to provide others in the informatics educational community with a model for analysis of curriculum in order to improve quality of student learning. Methods: We describe a case study where an academic informatics program realigned its course offerings to better reflect the HIM of today, and prepare for challenges of the future. Visionary leadership, intra-departmental self-analysis and alignment of the curriculum through defined mapping process reduced overlap within the $\mathrm{Cl}$ and HIM tracks. Teaching within courses was optimized through the work of core faculty collaboration.

Results: The analysis of curriculum resulted in reduction of overlap within course curriculum. This allowed for additional and new course content to be added to existing courses.

Conclusions: Leadership fostered an environment where top-down as well as bottom-up collaborative assessment activities resulted in a model to consolidate learning and reduce unnecessary duplication within courses. A focus on curriculum integration, emphasis on course alignment and strategic consolidation of course content raised the quality of informatics education provided to students. Faculty synergy was an essential component of this redesign process. Continuous quality improvement strategy included an ongoing alignment of curriculum and competencies through a comparative analysis approach. Through these efforts, new innovation was possible.

\section{Correspondence to:}

J. Valerius

Dept. of Medical Informatics \& Clinical Epidemiology Oregon Health \& Science University,

3181 SW Sam Jackson Park Rd.

Portland Oregon, 97239

United States

Email: valerius@ohsu.edu

\author{
Appl Clin Inform 2015; 6: 200-209 \\ http://dx.doi.org/10.4338/ACI-2014-10-CR-0086 \\ received: October 27, 2014 \\ accepted : February 18, 2015 \\ published: March 25, 2015 \\ Citation: Valerius J, Mohan V, Doctor D, Hersh W. Col- \\ laboration leads to enhanced curriculum. Appl Clin Inf \\ 2015; 6: 200-209 \\ http://dx.doi.org/10.4338/ACI-2014-10-CR-0086
}




\section{Introduction}

Clinical informatics (CI) education may be strengthened by recognizing how complementary professions can impact the improvement of healthcare, and by breaking down the silos that exist in traditional educational models. This article discusses a clinical informatics program that has successfully integrated the majority of its health information management (HIM) curriculum into an existing CI program, thereby reducing redundancy in curricula. As part of an ongoing effort to improve the CI program, a comparative analysis was conducted to determine where overlap of content between the HIM and CI curricula existed. This analysis was then reviewed in collaborative discussions among faculty members to determine how to enhance the overall informatics curriculum.

Historical background on the blurring of roles in HIM and CI is pertinent to the explanation of past efforts and of the ongoing integration of curricula. The following background discusses the Department of Medical Informatics and Clinical Epidemiology (DMICE) program and how the American Medical Informatics Association (AMIA), the American Health Information Management Association (AHIMA), and the Commission on Accreditation for Health Informatics and Information Management Education (CAHIIM) influence ongoing curriculum assessment to keep the programs at DMICE vital for student learning.

Since its inception in 1996, the DMICE informatics training program has grown to include graduate certificate tracks including CI in the earlier years and HIM in 2007, research master's, professional master's, and PhD programs. DMICE offers tracks in Bioinformatics and Computational Biology, HIM, and CI. Over time, this has resulted in more than 40 courses being offered in the program. A total of 558 people have earned 605 degrees and certificates.

\section{HIM}

As implementation of the electronic health record (EHR) increased after the Health Information Technology for Economic and Clinical Health (HITECH) Act of 2009, there has been a greater blurring of roles and responsibilities between the HIM workforce and the CI workforce [1].

In the mid-2000s, the HIM practitioners of the state of Oregon and at Oregon Health \& Science University (OHSU) discussed the burgeoning need for a new type of worker as the paper-based medical record was replaced by the EHR. The CI program at DMICE and the HIM practitioners envisioned a new program track in HIM that could bridge the gap.

In 2007, DMICE began program development of the HIM track. As described in JAHIMA [2], a gap analysis was performed to determine any overlap between the clinical informatics courses and the new HIM track. It was felt that with the adoption of advanced features of the EHR and the growing need for data analytics, there would be significant overlap between the roles of clinical informaticians and health information management professionals.

The initial HIM curriculum developed in 2007 incorporated 19 credits of the CI program into the 33-credit HIM graduate certificate program. Ongoing assessment and comparison of department curriculum has reduced redundancy: currently the HIM track is 31 credits (on an academic quarter system), with 22 of the credits a part of the core informatics curriculum shared with CI. This increase in the integration of different informatics courses at DMICE is due to leadership, faculty collaboration, and a commitment to enhancing the student's knowledge and skills.

Traditionally, the health information manager has governed the operational management of the medical-legal health record, most often in the acute care setting. With the diminished need for paper-based records, HIM has turned its attention to information governance and to business analytics of the data gleaned from the EHR. Clinical informaticians analyze data to improve patient care and to contribute new knowledge to the biomedical informatics field.

Contemporary health informatics and HIM programs may find that educational needs of informaticians and HIM students are similar. At DMICE the purposeful intersection of the HIM curriculum with the clinical informatics curriculum at the outset of the development provided several learning opportunities for the department:

1. Visionary leadership led an intra-departmental self-analysis program which indicated overlap between CI and HIM course in the DMICE catalog. 
2. Key faculty facilitated alignment of curriculum through mapping curricula to professional competencies and standards thus ensuring optimal teaching within courses. The director of the curriculum review project communicated with faculty course directors to discuss learning objectives, course content and syllabi in order to identify duplicative or missing content. She then worked with faculty members to make revisions and subsequently recommended the adoption of these changes by the departmental curriculum committee.

This allowed for creative opportunities to enrich curriculum and to identify other department goals.

\section{Professional Associations and Accreditation Body Curriculum Develop- ment}

AMIA, AHIMA, and CAHIIM have worked individually and together to build informatics curriculum for education.

\section{AMIA}

Development of informatics learning objectives and curricula is not a new phenomenon. As far back as 1998, the AAMC (Association of American Medical Colleges) delineated specific objectives for medical students within the domain of medical informatics [3]. In 2000, the International Medical Informatics Association (IMIA) issued recommendations on medical informatics education, and subsequently revised and updated them in 2010 [4]. In 2003 the AMIA Education Committee identified competencies in informatics [5].

As it became increasingly apparent that clinical informatics would emerge as a medical subspecialty, in 2009, AMIA issued a comprehensive paper that defined the boundaries of the discipline of clinical informatics [6], and delineated specific domains of core content. This paper attempted to identify specific knowledge and skills that trainees were expected to master, and drew from contributions describing program requirements for fellowship education [7], and defining the subspecialty [8].

Subsequently, in 2012 the AMIA Board issued a white paper [9] that defined the discipline of biomedical informatics and specified core competencies in the entire field, not just the clinical informatics domain related to training physicians.

\section{AHIMA}

In 2007, the AHIMA published Vision 2016: A Blueprint for Quality Education in Health Information Management. This white paper was the result of the AHIMA Board of Directors' charge to the 2006-2007 Education Strategy Committee:

To ensure the future of the health information management profession and the broader health informatics profession to achieve a strong leadership role to transform healthcare through quality health information, for the successful deployment of electronic health records, personal health records, and the national health information network p. 4 [10].

In 2014 the AHIMA's Council for Excellence in Education (CEE) published an associate, baccalaureate, and graduate degree Health Information Management curriculum competency map. One area in particular, (Domain III: Informatics, Analytics and Data Use) clearly delineates the expectation of all levels of HIM education to broaden the scope of knowledge in informatics.

\section{Definition}

Creation and use of Business health intelligence; select, implement, use and manage technology solutions; system and data architecture; interface considerations; information management planning; data modeling; system testing; technology benefit realization; analytics and decision support; data visualization techniques; trend analysis; administrative reports; descriptive, inferential and advanced statistical protocols and analysis; IRB; research; patient-centered health information technologies; health information exchange; data quality p. 4 [11]. 


\section{CAHIIM}

From 2008-2010, CAHIIM developed two curricula for consideration by universities for accreditation: Masters in Health Information Management (2008) and a Masters in Health Informatics (2010) to meet the growing need within the HIM/HI workforce for trained professionals in the field. These programs addressed higher level information/informatics content. [12] In 2006, AMIA and AHIMA identified work force shortages in the EHR area including informatics. [13] In 2008, AMIA and AHIMA collaborated on a Joint Workforce Task Force report titled Health Information Management and Informatics Core Competencies for Individuals Working with Electronic Health Records (EHRs) [14]. In September, 2014, AMIA joined the CAHIIM as an organizational member. A health informatics council will include AMIA leaders for the revision of the 2010 Accreditation Standards [15].

\section{Methods}

A new HIM track was developed in 2007 to meet the growing need for HIM practitioners in Oregon and throughout the U.S. The department sought and received accreditation of the HIM track in 2009 under the HIM Baccalaureate Degree accreditation Standards. Further, the department sought and received CAHIIM accreditation of the Health Informatics Masters track (referred to as the CI track) in 2012.

As AMIA, AHIMA, and CAHIIM expanded the knowledge of informatics for professionals in specific informatics domains, DMICE program leadership perceived the increasing confluence of learning concepts between different domains of informatics.

In 2009, DMICE was awarded $\$ 3$ million in funding from the Office of the National Coordinator (ONC) for Health IT to train informaticians. This funding led to an expansion of course offerings as well as to an increase in student enrollment. After the successful conclusion of this grant, the need to increase efficiencies in the course catalog and to consolidate courses was identified, particularly since student enrollment was expected to decline once scholarship programs ended. The need to increase efficiency was tempered by the need to maintain the breadth of the course catalog, a distinguishing feature of the program. Leadership organized a one-day retreat to engage faculty in a highlevel review of the curriculum. These discussions were particularly effective in fostering a collaborative process to plan the restructuring of course offerings and to determine which content would best reflect the future aspirations of the department.

\section{Comparative analysis in curriculum transformation in DMICE reduces redundancy and enhances curriculum}

\section{The development of the HIM program.}

The approach to developing the HIM curriculum included a comparison of the existing biomedical informatics course learning objectives and content with standards and competencies established by the CAHIIM. Core faculty participated in course review and engaged in discussions with the HIM Program Director to determine where overlap and gaps existed. When gaps were found to exist, new courses and new modules embedded within existing courses were developed to meet specific HIM core competencies.

\section{Comparison of AMIA Clinical Informatics and CAHIIM Masters in Health In- formatics 2010 competencies.}

We also identified individual courses that fit within the framework of a comprehensive informatics education, and mapped their content to both the AMIA CI competencies (as outlined by Gardner, et al in 2010), and to the CAHIIM competencies for health informatics (HI) accreditation. In $>$ Figure 1 , courses marked with an "X“ satisfy both AMIA and CAHIIM competencies.

Further, another review of the entire curriculum was conducted to create a granular, comprehensive inventory of course content that reflected specific competencies. The inventory identified the 
subset of DMICE courses that included all of the competencies the program required in order for students to meet the learning objectives. The inventory also allowed us to identify areas of duplication among courses. $>$ Figure 2 illustrates how each course in the program addressed individual AMIA and CAHIIM competencies and in what form (Lecture, Article, Reading, Book, or Exercise). As a result of this inventory, course instructors had access to hard data that facilitated collaboration in the effort to consolidate redundant information. For example, an examination of two similar courses, 583-IT in Health Information Practice in the HIM track and 512-Clinical Information Systems in the CI track, revealed significant overlap in the discussion of electronic health records. Following a module-by-module comparison of the two courses, it was determined that only one course was needed to include required content relevant to both tracks. Course 512 was updated to include examples of HIM-specific issues with EHRs. Content in course 583 that was not duplicative was distributed among other HIM-track courses. As a result, 583 was retired without sacrificing needed content while simultaneously eliminating course overlap. Students were then able to obtain all of the required content by taking just one course, rather than two.

Similarly, a comparison of 587-Research, Statistics, and Quality Applied to Health Information Practice in the HIM track and 537-Healthcare Quality in the CI track produced comparable results. Duplicative content regarding healthcare quality measures was consolidated into 537 and HIM-specific healthcare quality issues were added to that course. Discrete content in 587 was distributed among other HIM-track courses. In this way, 587 was retired from the catalog with no loss of core content.

In other instances, the elimination of duplicative content freed up space within individual courses, allowing instructors to incorporate important new topics. For example, course mapping, identified specific courses that leant themselves to the addition of material from the emerging domain of data analytics.

Further, pursuant to this intensive review, faculty members were able to collaborate to create a new ethics course focusing specifically on ethical topics prevalent in informatics, thereby enhancing the curricula in both tracks. In addition, new initiatives were introduced to increase collaboration with industry such as the creation of an innovation laboratory at DMICE. The lab was developed not only as a means to maintain a cutting-edge curriculum but also to allow students hands-on access to commercial hardware and software products relevant to their careers in CI and HIM.

\section{Integrating curriculum improvement processes into university $\mathrm{Cl}$ and depart- ment assessment activities.}

The comparative analysis of the curriculum is in concert with the university's new course evaluation system. The institution's internal assessment council further contributes to the improved quality of the curriculum by requiring the annual submission of a "State of the Program" report. This report is incorporated into the submission sent to the regional accreditation agency every five years. The department also undergoes an annual review process by CAHIIM, a process that is required for HIM and HI accreditation renewal. The practicum/internship evaluation system implemented in 2010 solicits valuable feedback from mentors at sponsoring institutions. The breadth and depth of the evaluation processes ensure the continuation of high-quality programs for students.

\section{Discussion}

\section{Enrichment}

As the domain of HIM has matured, there has been a tendency toward growing overlap among topics taught in HIM courses and in CI courses. Focusing on curriculum integration between the complementary professional fields of HIM and CI has reduced unnecessary duplication of learning activities and has enhanced coursework for students. This process of integration is particularly relevant at DMICE, since the HIM program has now been a distinct entity for 7 years. The process of alignment and strategic consolidation of course content with an aim to reduce redundancies and topic duplication has raised the quality of informatics education provided to students. 


\section{Collaboration}

Faculty actively collaborated with the HIM Program Director to analyze the CI curriculum with the intent of determining overlap with HIM content. This essential activity was enhanced by understanding the historical and current overlap of AMIA and AHIMA and informed faculty of the necessity to work together to enhance curriculum for student learning.

Curricula cannot be developed in isolation; engagement with peers is an essential aspect of crosspollination of ideas. The department chair and many core faculty members are active in AMIA and AHIMA which assures that best practices are incorporated into the curriculum

\section{Alignment}

The process of curricular assessment began with a bottom-up approach where faculty met to discuss how best to align courses to a common goal. As the university's assessment plan changed, a top down approach was also implemented, which accelerated the process of curriculum change. However, because of the initial collaborative efforts among faculty members, the top down approach became a collaborative and non-threatening activity as well.

One lesson learned in this process was the importance of ongoing alignment of curriculum through a comparative analysis approach of curriculum and competencies. Although professional competencies changes are periodic, faculty in this department frequently seek to uncover new and innovative knowledge and skill sets needed for graduates. Yearly updates on the program, accreditation reports, and university assessment build a heightened sense of the importance of active faculty involvement. The department chair's leadership is essential to the process.

\section{Expansion in new directions}

Another lesson learned was that creating a collaborative environment for faculty and reducing redundancy in courses fostered greater innovation within the department. Discussions among faculty members led to seeking new avenues to advance the department's goal of becoming a leader in informatics. In 2012, the department launched an innovation laboratory to facilitate the partnership of industry and academia to work on informatics and analytics projects. An offshoot of the lab was the development and deployment of an educational instance of a commercial EHR, which was subsequently utilized to create and offer an EHR lab course [16]. This lab course allowed HIM and HI students to gain practical exposure to the EHR and gain hands-on experience of theoretical concepts.

The advancement of informatics in CI and HIM, the avenues chosen to assess curriculum, and the overall leadership of the department, continue to engage faculty in breaking down barriers between fields. As a result, integrated learning benefits faculty and students alike.

Relevance to the Health Informatics Educational Programs

These methods provide educational institutions with the means to evaluate course content against national competencies with the aims of improving curriculum and eliminating redundancy. In doing so, curriculum is enhanced.

\section{Conflicts of Interest}

The authors declare that they have no conflicts of interest.

Protection of Human and Animal Subjects

Human and/or animal subjects were not included in the project. 


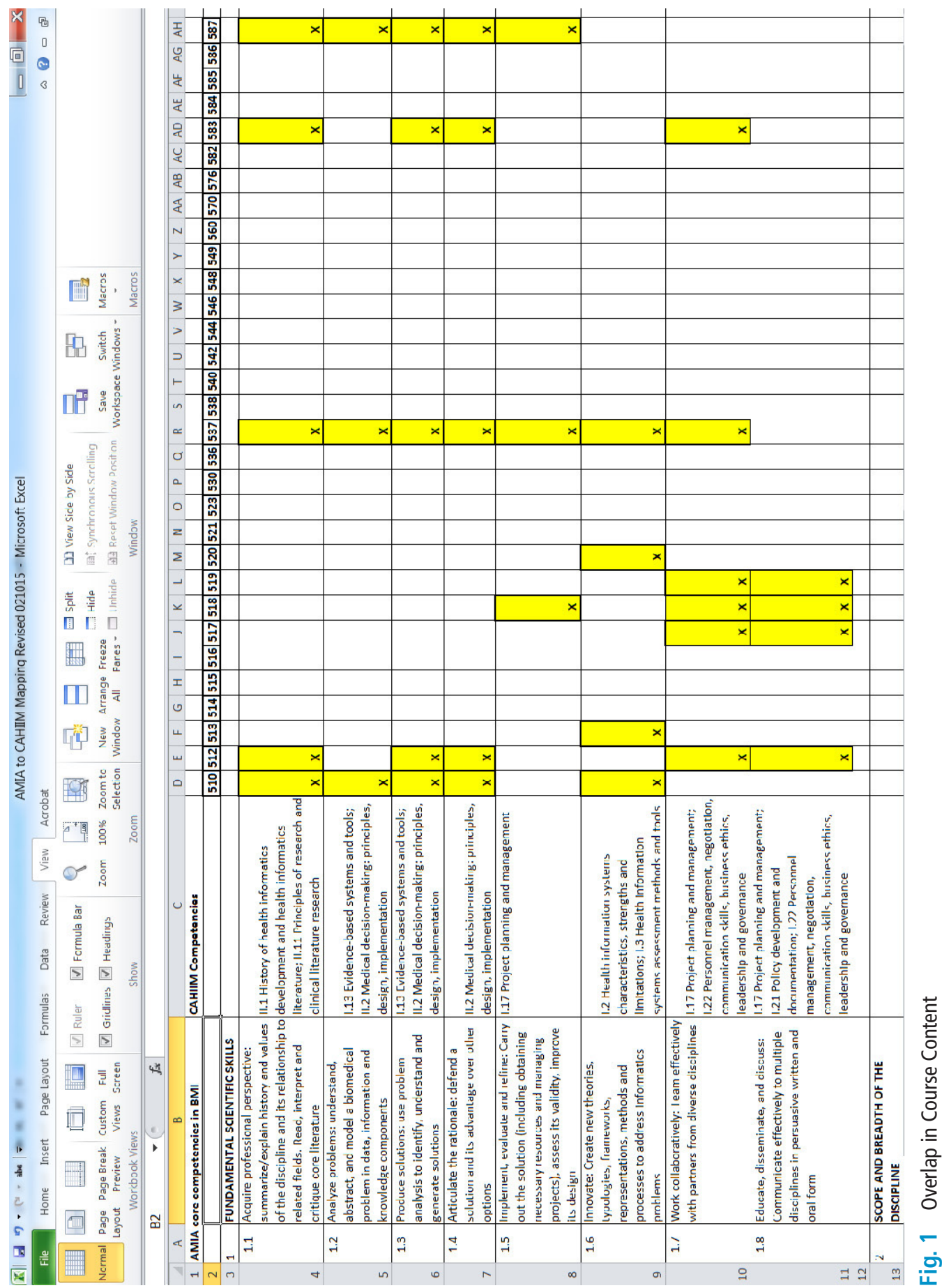




\section{A}

\section{B}

AMIA to CAHIIM Mapping Course Numbers and Titles

2

35510 Introduction to Biomedical Informatics

$4 \quad 512$ Clinical Information Systems

$5 \quad 513$ Electronic Health Record Lab

$6 \quad 514$ Information Retrieval

7515 Ethical, Legal and Social Issues in Informatics (Retired)

$8 \quad 516$ Standards and Interoperability

$9 \quad 517$ Organizational Behavior and Management

$10 \quad 518$ Project Management

11519 Business of Healthcare Informatics

12520 Consumer Health Informatics

$13 \quad 521$ Public Health Informatics

14523 Clinical Research Informatics

$15 \quad 530$ Practice of Healthcare

16536 Evidence-based Medicine

$17 \quad 537$ Healthcare Quality

$18 \quad 538$ Medical Decision Making

19540 Introduction to Computer Science with Java Programming

$20 \quad 542$ Computer Networks

$21 \quad 544$ Databases

$22 \quad 546$ Software Engineering

$23 \quad 548$ Human Computer Interaction

$24 \quad 549$ Health Information Privacy and Security

$25 \quad 560$ Design and Evaluation in Health Informatics

26570 Scientific Writing and Communication for Informatics Students

27576 Managing Ethics in Biomedical Informatics (Replaced BMI 515 and BMI 586)

$28 \quad 582$ Health Care Data Management

29583 IT in Health Information Practice (Retired)

$30 \quad 584$ Clinical Classification Systems \& Applied Reimbursement Methodologies

31585 Applied Management in Health Information Practice (Retired)

32586 Applied Legal and Ethical Issues in Health Information Practice (Retired)

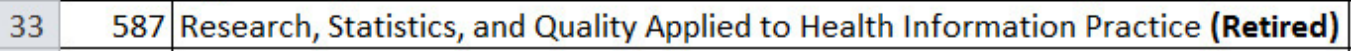

Fig. 1a Course Numbers and Titles 


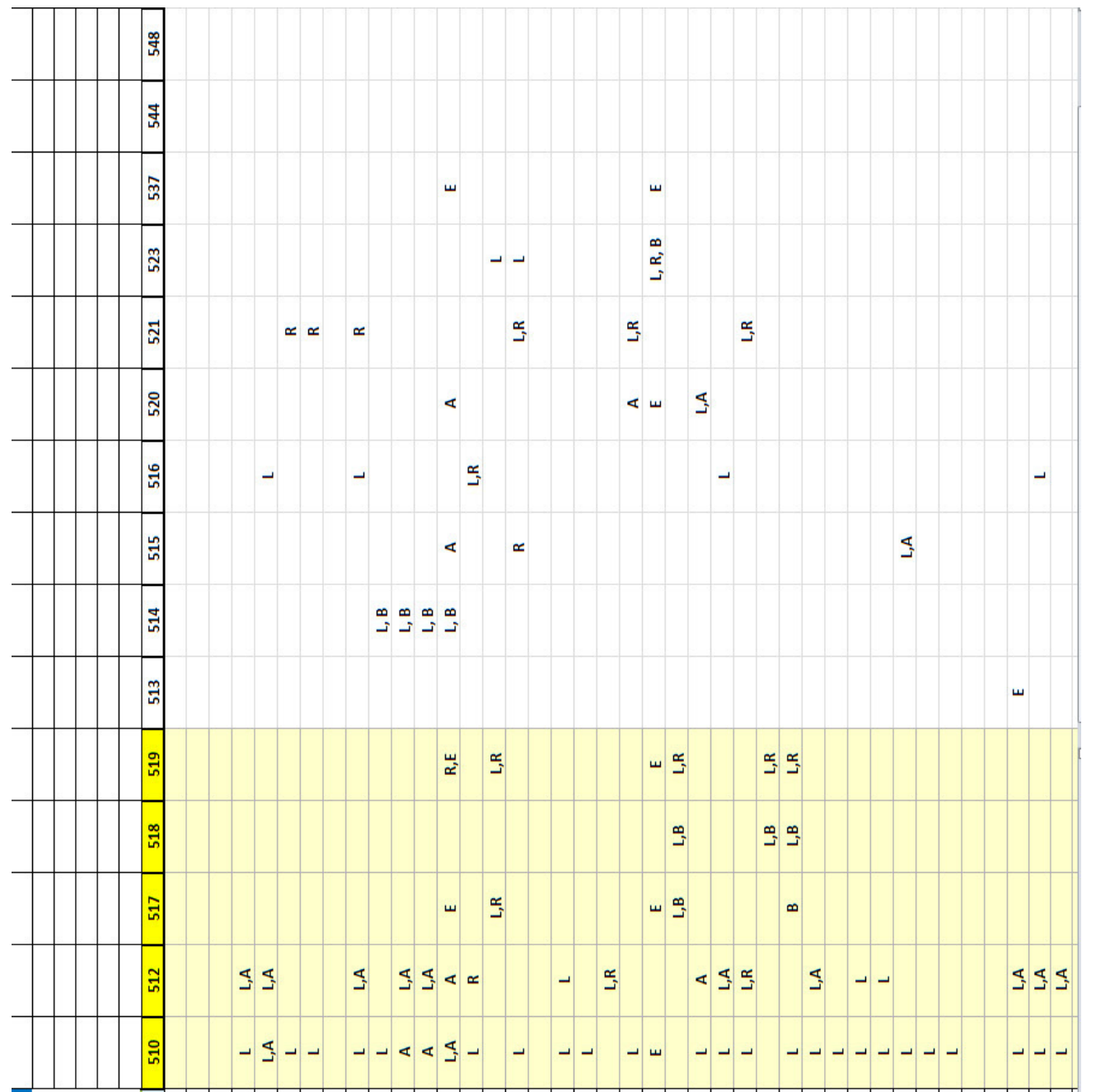

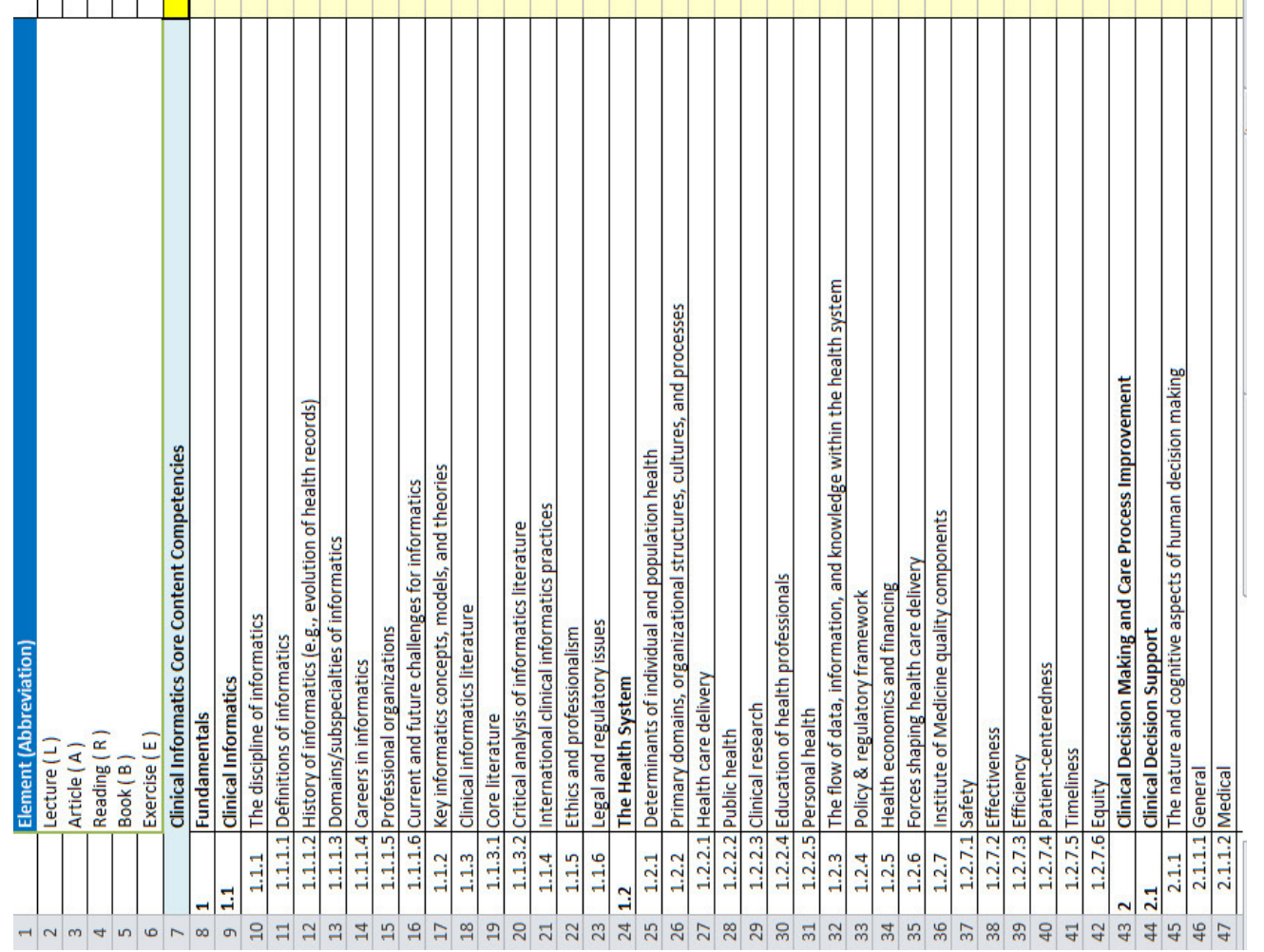

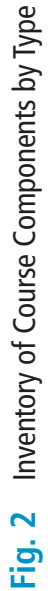




\section{References}

1. American Health Information Management Association. Joint AMIA/AHIA summary of their relationship and links to the informatics fields. 2012 Jan. Available from: http://www.amia.org/joint-amia-ahimasummary

2. Hersh R, Valerius J D. A tale of two professions: Health information management and biomedical/health informatics converge at OHSU. Journal of AHIMA 2013; 84 (10): 38-41.

3. Association of American Medical Colleges. Learning objectives for medical student education: Guidelines for medical schools. 1998 Jan. Available from: https://webcampus.drexelmed.edu/professionalism/ AAMCMedicalSchoolObjectivesProject.pdf

4. Mantas J, Ammenwerth E, Demiris G, Hasman A, Haux R, Hersh W, Hovenga E, Lun KC, Marin H, Martin-Sanchez F, Wright G; IMIA Recommendations on Education Task Force. Recommendations of the International Medical Informatics Association (IMIA) on education in biomedical and health informatics. First Revision. Methods Inf Med 2010; 49: 105-120.

5. American Medical Informatics Association. Education committee report: Competencies in biomedical and health informatics: A policy paper, internal document. 2002.

6. Gardner RM, Overhage JM, Steen EB, Benson S, Munger BS, Holmes JH, Williamson JJ, Detmer DE. Core content for the subspecialty of clinical informatics. J Am Med Inform Assoc 2009; 16: 153e7. doi: 10.1197/jamia.M3045.

7. Safran C, Shabot MM, Munger BS, Holmes JH, Steen EB, Lumpkin JR, Detmer DE; AMIA Board of Directors. Program requirements for fellowship education in the subspecialty of clinical informatics. J Am Med Inform Assoc 2009; 16: 158-166. J Am Med Inform Assoc 2009; 16(2): 158-166. doi: 10.1197/jamia.M3046. PMCID: PMC2649323

8. Detmer DE, Lumpkin JR, Williamson JJ. Defining the medical subspecialty of clinical informatics. J Am Med Informatics Assoc 2009; 16: 167-168.

9. Kulikowski CA, Shortliffe EH, Currie LM, Elkin PL, Hunter LE, Johnson TR, Kalet IJ, Lenert LA, Musen MA, Ozbolt JG, Smith JW, Tarczy-Hornoch PZ, Williamson JJ. AMIA Board white paper: definition of biomedical informatics and specification of core competencies for graduate education in the discipline. J Am Med Inform Assoc 2012; 19(6): 931-938. doi: 10.1136/amiajnl-2012-001053. Epub 2012 Jun 8.

10. AHIMA. Vision 2016: A blueprint for quality education in health information management. 2007. Available from: http://library.ahima.org/xpedio/groups/public/documents/ahima/bok1_035517.pdf

11. Council for Excellence in Education Health Infomatics and Health Information Management. Side by side progression map of associate, baccalaureate, and graduate HIM curricula. 2013. Available from: http://ahimafoundation.org/downloads/pdfs/2014\%20Side-by-Side_Curriculum_Map.pdf

12. Commission on Accreditation for Health Informatics and Information Management Education. 2014. Available from: Cahiim.org

13. American Health Information Management Association, American Medical Informatics Association. Building the work force for health information transformation. 2006 Feb. Available from: http://www. amia.org/sites/amia.org/files/Workforce_2006.pdf

14. American Health Information Management Association, American Medical Informatics Association. Joint work force task force: Health information management and informatics core competencies for individuals working with electronic health records. 2008 Oct. Available from: http://library.ahima.org/xpedio/ groups/public/documents/ahima/bok1_040723.pdf

15. American Medical Informatics Association. AMIA joins CAHIIM to lead informatics program accreditation. 2014 Sep. Available from: http://www.amia.org/news-and-publications/press-release/amia-joinscahiim-lead-informatics-program-accreditation

16. Mohan V, Hersh WR. Development and evaluation of an electronic health record configuration and customization laboratory course for clinical informatics students. Stud Health Technol Inform 2013;192: 1122 . 